\title{
Continuing to Confront COPD International Patient Survey: methods, COPD prevalence, and disease burden in 2012-20I3
}

This article was published in the following Dove Press journal:

International Journal of COPD

6 June 2014

Number of times this article has been viewed

\author{
Sarah H Landis' \\ Hana Muellerova' \\ David M Mannino ${ }^{2}$ \\ Ana M Menezes ${ }^{3}$ \\ MeiLan K Han ${ }^{4}$ \\ Thys van der Molen ${ }^{5}$ \\ Masakazu Ichinose 6 \\ Zaurbek Aisanov ${ }^{7}$ \\ Yeon-Mok $\mathrm{Oh}^{8}$ \\ Kourtney J Davis? \\ 'Worldwide Epidemiology, \\ GlaxoSmithKline, Uxbridge, UK; \\ ${ }^{2}$ University of Kentucky College of \\ Public Health, Lexington, KY, USA; \\ ${ }^{3}$ Federal University of Pelotas, Pelotas, \\ Brazil; ${ }^{4}$ Division of Pulmonary and \\ Critical Care, University of Michigan, \\ Ann Arbor, MI, USA; ${ }^{5}$ University \\ Medical Center Groningen, \\ Groningen, Netherlands; ${ }^{6}$ Tohoku \\ University Graduate School of \\ Medicine, Sendai, Japan; 'Pulmonology \\ Research Institute, Moscow, Russia; \\ ${ }^{8}$ University of Ulsan College of \\ Medicine, Asan Medical Center, \\ Seoul, South Korea; ${ }^{9}$ Worldwide \\ Epidemiology, GlaxoSmithKline, \\ Wavre, Belgium
}

Purpose: The Continuing to Confront COPD International Patient Survey aimed to estimate the prevalence and burden of COPD globally and to update findings from the Confronting COPD International Survey conducted in 1999-2000.

Materials and methods: Chronic obstructive pulmonary disease (COPD) patients in 12 countries worldwide were identified through systematic screening of population samples. Telephone and face-to-face interviews were conducted between November 2012 and May 2013 using a structured survey that incorporated validated patient-reported outcome instruments. Eligible patients were adults aged 40 years and older who were taking regular respiratory medications or suffered with chronic respiratory symptoms and reported either 1) a physician diagnosis of COPD/emphysema, 2) a physician diagnosis of chronic bronchitis, or 3) a symptom-based definition of chronic bronchitis. The burden of COPD was measured with the COPD Assessment Test (CAT) and the modified Medical Research Council (mMRC) Dyspnea Scale.

Results: Of 106,876 households with at least one person aged $\geq 40$ years, 4,343 respondents fulfilled the case definition of COPD and completed the full survey. COPD prevalence ranged from $7 \%$ to $12 \%$, with most countries falling within the range of $7 \%-9 \%$. In all countries, prevalence increased with age, and in all countries except the US was greater among men (range $6 \%-14 \%$ ) than among women (range 5\%-11\%). A significant disease burden was observed when considering COPD symptoms or health status, and showed wide variations across countries. Prevalence of moderate-to-severe dyspnea (mMRC scale $\geq 2$ ) ranged from $27 \%$ to $61 \%$, and mean CAT score ranged from 16.0 to 24.8 , indicating medium-to-high impairment.

Conclusion: This survey, representing 12 countries, showed similar rates of estimated COPD prevalence across countries that were higher than those reported a decade ago in the original Confronting COPD International Survey. A significant burden of COPD was demonstrated by symptoms and health care-resource use, similar to that reported in the original survey.

Keywords: chronic obstructive pulmonary disease, patient perspective, prevalence, patientreported outcomes

\section{Introduction}

Chronic obstructive pulmonary disease (COPD) is a progressive inflammatory disease, associated with a global social and economic burden that is projected to increase in both developed and developing countries, due to the continued use of tobacco and biomass fuels, and aging populations. ${ }^{1-3}$ Many patients with COPD suffer an impact on their quality of life ${ }^{4,5}$ and activities of daily living. ${ }^{6}$ Exacerbations of COPD can have a major impact on these activities, and are a risk factor for hospitalizations, mortality, and worse disease progression, ${ }^{7-11}$ placing a large economic burden on health care systems. ${ }^{12}$
Correspondence: Sarah H Landis Worldwide Epidemiology, GlaxoSmithKline, Stockley Park West, Uxbridge, Middlesex UBII IBT, UK Email sarah.h.landis@gsk.com 
A systematic review of the global population-based prevalence estimates of COPD, chronic bronchitis, and/or emphysema in adults aged 40 years and older reported a pooled prevalence of $9 \%-10 \% ;{ }^{13}$ however, significant heterogeneity across countries and widely differing methodologies for assessing prevalence made comparisons between studies difficult to interpret. The use of standardized spirometry criteria for quantifying the prevalence of COPD in adults aged 40 years and older shows similar intercountry variation, but generally demonstrates higher prevalence rates than earlier studies. ${ }^{14,15}$

Past global population surveys have highlighted the high morbidity burden associated with COPD. The original Confronting COPD International Survey conducted in Europe and North America in 2000 showed that many patients with diagnosed COPD or symptoms consistent with chronic bronchitis underestimated their symptoms and severity of disease, as evidenced by a high proportion experiencing limitations to daily activities and a frequent use of health resources. ${ }^{16}$ Similar findings were reported in the BREATHE study, conducted in eleven countries in the Middle East, North Africa, and Pakistan. ${ }^{17,18}$ Fletcher et al reported a high impact of COPD in a working-age population, with approximately $40 \%$ of patients retiring early due to COPD. ${ }^{19}$ The Hidden Depths of COPD online survey also evaluated a working-age COPD population (mean age 53 years) across 14 countries, demonstrating a significant impact on daily activities and high levels of exacerbations and health care-resource use, despite the majority of patients regarding their disease as "under control". ${ }^{20}$

The Continuing to Confront COPD International Survey replicated the original Confronting COPD International Survey 13 years later, and aimed to estimate COPD prevalence and disease burden from both the patient and physician perspective across 12 countries. This paper describes the Continuing to Confront COPD Patient Survey methodology, and reports on the COPD prevalence and patient-reported burden by country.

\section{Materials and methods Study design and subject selection}

The Continuing to Confront COPD International Patient Survey was a population-based survey of adults fulfilling a case definition of COPD, conducted in 12 countries (Brazil, France, Germany, Italy, Japan, Mexico, Netherlands, Russia, South Korea, Spain, UK, USA) between November 2012 and May 2013.

COPD patients were identified systematically by screening probability samples of households using three sampling approaches. In countries with high rates of telephone coverage (France, Germany, Italy, Netherlands, Spain, UK, USA), random-digit dialing (RDD) of a sample of landline-telephone households was conducted, and respondents were interviewed by computer-assisted telephone interviewing (CATI). The sampling was stratified by region, and produced a nationally representative sample of the urban/rural population. In countries with variable or poor telephone coverage (Brazil, Mexico, Russia, South Korea), households were sampled by area-probability sampling of urban areas, and respondents were interviewed face to face. In Japan, where neither of the aforementioned methods was feasible, an online health panel that was demographically representative of the Japanese population was used for sampling and screening COPD patients. As with the other countries, respondents from the online panel who met the case definition of COPD were then interviewed by CATI.

With all sampling methods, households were initially screened for any persons aged 40 years or older; respondents were then screened for case definition of COPD according to the questionnaire qualifying criteria. Prior to completion of the survey, all respondents gave verbal consent to participate, and could terminate the interview at any time. Participation in the survey was voluntary, and all subject data were confidential and anonymous. This survey qualified for institutional review board exemption (see full details in the Supplementary materials). Further details about each sampling method can be found in the Supplementary materials.

\section{Case definition}

The case definition for COPD in this survey was adults aged 40 years and older meeting one of the following definitions:

- physician diagnosis of COPD, chronic obstructive airway disease, or emphysema, and either regularly used medication to treat these conditions or had chronic cough with phlegm most days

- physician diagnosis of chronic bronchitis and either regularly used medication to treat this condition or had chronic cough with phlegm most days

- chronic bronchitis defined by symptomatology (cough and sputum production on most days for at least 3 months in the year for at least 2 consecutive years) ${ }^{21,22}$ and either regularly used medication to treat this condition or had chronic cough with phlegm most days.

Eligibility was determined using a hierarchal approach: a respondent who qualified with a physician diagnosis of 
COPD, chronic obstructive airway disease, or emphysema was not further queried to see if they also would qualify based on physician diagnosis of chronic bronchitis. Only patients who did not report any of the physician-diagnosed conditions were assessed for the symptom-based definition of chronic bronchitis. Therefore, it was possible that a respondent could have suffered from more than one condition.

\section{Data collection}

Interviews were conducted using a structured questionnaire with similar content to the original Confronting COPD International Survey, supplemented with validated patient-reported outcome (PRO) instruments, including the Work Productivity and Activity Impairment (WPAI) Questionnaire, ${ }^{23}$ the COPD Assessment Test (CAT), ${ }^{24}$ the modified Medical Research Council (mMRC) Dyspnea Scale, ${ }^{25}$ the eight-item Morisky Medication Adherence Scale, ${ }^{26}$ and the Patient Activation Measure (PAM) ${ }^{27}$ An mMRC cutoff point of $\geq 2$ indicates moderate-to-severe breathlessness upon physical exertion. ${ }^{25}$ The total CAT score can range from 0 (best health status) to 40 (worst health), with scores $\geq 10$ indicating medium-tovery high impact of COPD on the patient's life. ${ }^{28}$ Full details of the PRO instruments can be found in the Supplementary materials.

Subjects were further questioned about the severity of their disease, daytime and nighttime symptoms, treatment with antibiotics/corticosteroids, emergency room visits and hospitalizations due to "worsening breathing problems", attitudes and views toward health care professionals and treatments, and passive smoking/environmental smoke/dust/ fumes exposure. Respondent smoking status was defined as current smoker (presently smoking cigarettes/cigars/pipe at least once a day), former smoker (not currently smoking, but had smoked at least 100 cigarettes in their lifetime and at some point smoked on a daily basis), or never-smoker (smoked fewer than 100 cigarettes in their lifetime or never smoked at all). A recall of a physician diagnosis of preselected comorbidities was queried (asthma, hypertension, heart attack, heart failure, stroke, cancer). Body mass index was calculated based on self-reported weight and height. ${ }^{29}$ The questionnaire was translated locally by professional translators experienced in health-survey research and reviewed by at least two independent translators, and piloted within each country. Validated translations of the PRO instruments were used. Interviews were conducted in the local language using the translated questionnaire, and had an average duration of 36 minutes (details by country shown in the Supplementary materials). For quality-control purposes, a minimum of $10 \%$ of interviews (all sampling methods) were validated by recontact or review of recorded interviews.

\section{Sample population and statistical analysis}

The sampling and screening process identified 106,876 households with a respondent aged 40 years and older who agreed to be interviewed (Figure 1). Of these, 73,745 households provided valid responses and completed the screening process

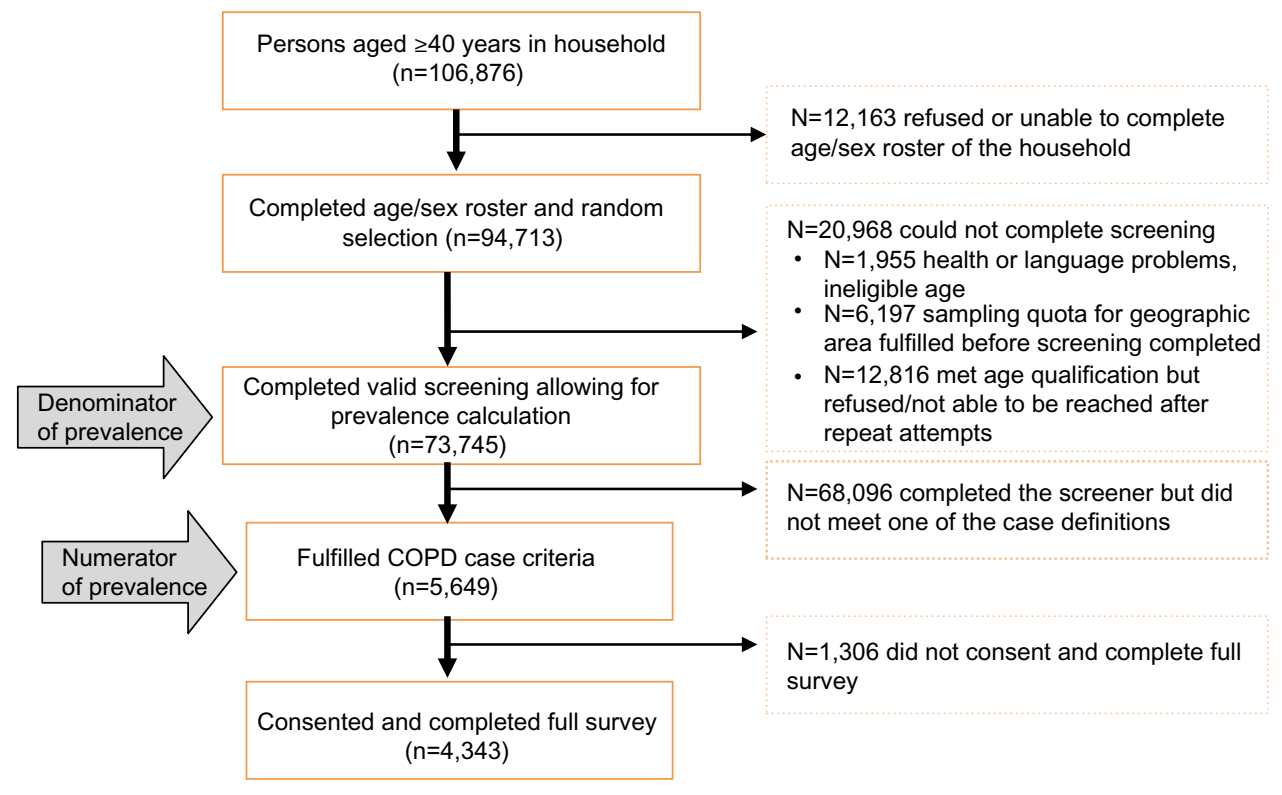

Figure I Study-consort diagram.

Abbreviation: COPD, chronic obstructive pulmonary disease. 
(denominator of the prevalence calculation). A valid response was defined as a definitive response to all the qualifying questions; respondents who did not provide a response or who were unable to complete the screening section of the questionnaire (eg, did not know, refusal, interruption, unable to be interviewed due to poor health) were not included. Out of this cohort, 5,649 respondents fulfilled the case definition of COPD (numerator of the prevalence calculation). Response rates ranged from $25 \%$ in the UK to $74 \%$ in Brazil. A total of 4,343 respondents fulfilled the case definition of COPD and consented to complete the full survey (final survey population). (A detailed flowchart is available in the Supplementary materials, Figure S1). About a quarter of the final survey population $(n=1,001)$ were from the US, with the remaining eleven countries each providing a sample of approximately 300 patients. This sample size allowed for a sample precision for the prevalence estimates of between $0.3 \%$ to $1.1 \%$ at the 95\% confidence level.

To minimize the effect of sex and age imbalances in the sampling and screening process, the final survey population ( $n=4,343$ ) were weighted by age and sex according to the latest census data available in each country. In addition, data combining all 12 countries were weighted according to population size. Therefore, all percentages presented in the paper are weighted percentages. Descriptive statistics have been used to present all data.

\section{Results}

\section{COPD prevalence}

The overall COPD prevalence ranged from $7 \%$ to $12 \%$, with the majority of individual country estimates ranging from $7 \%$ to $9 \%$ (Figure 2). Prevalence rates were generally higher among men (range 6\%-14\%) than among women (range 5\%-11\%). This pattern was consistent across all countries, with the exception of the US (men $6.2 \%$, women $7.1 \%$ ) (Table 1). In all countries, prevalence increased with age.

\section{Demographic data}

Among the 4,343 respondents who fulfilled the case definition of COPD and consented to complete the full survey, $45 \%$ qualified with a physician diagnosis of either COPD, chronic obstructive airway disease, or emphysema; $45 \%$ had a physician diagnosis of chronic bronchitis; and 10\% had symptom-based chronic bronchitis (Table 2). About half of the respondents were males (48\%). There was variability in respondent age across countries, with the highest proportion of younger patients aged 40-49 years in Brazil (31\%), Japan (28\%), and Russia (27\%), and the proportion of those 70 years and older was greatest in France (44\%) and Spain (39\%). Thirty percent of all patients were in current employment, ranging from $17 \%$ in the UK to $53 \%$ in Russia. Hypertension (45\% [range 20\%-62\%]) and asthma (42\% [range $12 \%-54 \%$ ]) were the most commonly reported comorbidities.

\section{Smoking history and other exposure}

Thirty-six percent of the total weighted population were classified as never smokers (range 24\%-64\%), 37\% as former smokers (range $27 \%-47 \%$ ), and $28 \%$ as current smokers (10\%-34\%) (Table 2 and Figure 3). Overall, men (79\%) were more likely than women (50\%) to report being current/former smokers. Among both sexes, current/former smokers were more likely to report that they also had environmental exposure, including passive tobacco smoke in the home or smoke/

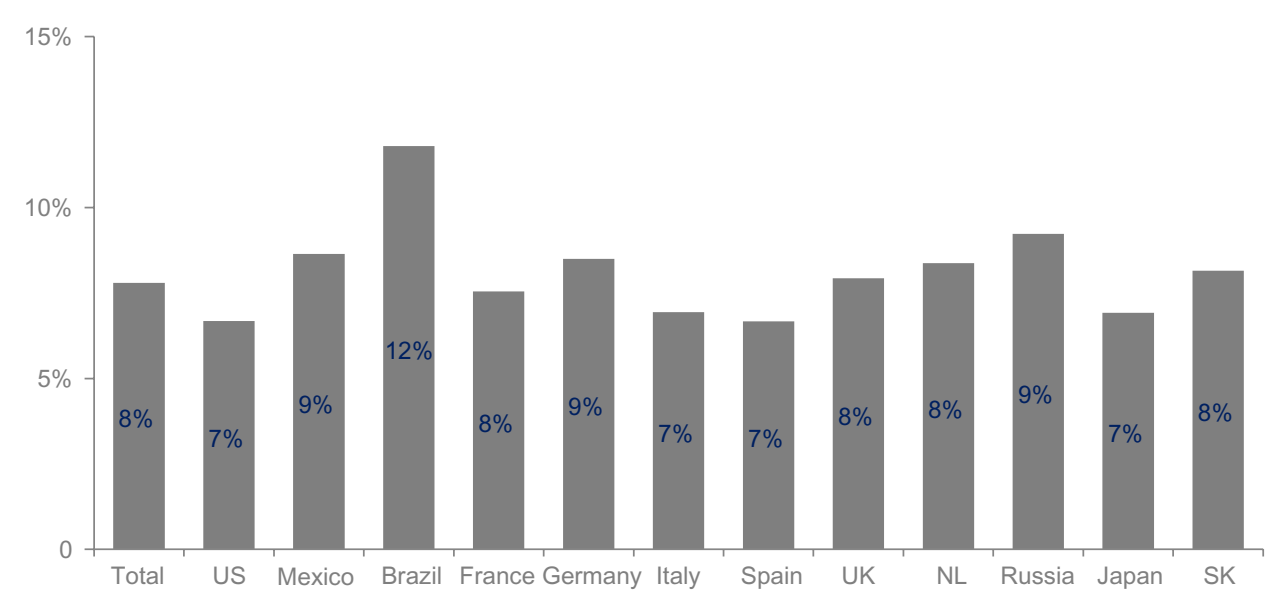

Figure 2 Estimated prevalence of chronic obstructive pulmonary disease by country. Prevalence was weighted by country size. Abbreviations: NL, Netherlands; SK, South Korea. 
Table I Estimated overall household COPD prevalence by country, and split by sex and age (years)

\begin{tabular}{|c|c|c|c|c|c|c|c|}
\hline \multirow[t]{2}{*}{ Country } & \multicolumn{7}{|c|}{ Estimated household COPD prevalence (\%) } \\
\hline & Overall & Males & Females & Age $40-49$ years & Age $50-59$ years & Age 60-69 years & Age $\geq 70$ years \\
\hline USA & 6.7 & 6.2 & 7.1 & 3.9 & 6.4 & 6.7 & 8.9 \\
\hline Mexico & 8.6 & 11.2 & 7.4 & 4.2 & 6.9 & 14.2 & 18.1 \\
\hline Brazil & 11.8 & 13.5 & 10.7 & 8.7 & 11.6 & 13.1 & 17.8 \\
\hline France & 7.5 & 8.3 & 7.0 & 3.8 & 5.9 & 8.2 & 11.2 \\
\hline Germany & 8.5 & 10.1 & 7.6 & 5.8 & 8.2 & 10.5 & 13.0 \\
\hline Italy & 7.0 & 8.7 & 5.5 & 4.7 & 5.7 & 7.5 & 9.2 \\
\hline Spain & 6.5 & 8.4 & 5.0 & 3.5 & 5.1 & 6.6 & 8.7 \\
\hline UK & 8.1 & 9.5 & 7.3 & 4.9 & 6.9 & 8.7 & 10.6 \\
\hline Netherlands & 8.2 & 8.9 & 7.7 & 4.6 & 7.6 & 10.8 & 12.5 \\
\hline Russia & 9.2 & 11.4 & 8.3 & 7.2 & 9.9 & II.I & 15.0 \\
\hline Japan & 7.0 & 8.7 & 5.5 & 5.5 & 6.5 & 8.8 & 14.2 \\
\hline South Korea & 8.2 & II.I & 5.9 & 4.6 & 7.2 & 9.5 & 15.6 \\
\hline Total & 7.8 & 8.6 & 7.2 & 5.3 & 7.3 & 8.5 & 11.0 \\
\hline
\end{tabular}

Note: Total prevalence was weighted by country size.

Abbreviation: COPD, chronic obstructive pulmonary disease.

dust/fumes at home or in the workplace (Figure 3). Among the total weighted population, $18 \%$ of respondents indicated neither smoking history nor environmental exposures. The proportion of patients self-reporting an asthma diagnosis was not markedly different in this nonsmoking/not environmentally exposed group (44\%) compared to the other three smoking/ environmental exposure categories (smokers/environmentally exposed, 43\%; smokers/not environmentally exposed, 34\%; nonsmokers/environmentally exposed, 49\%).

\section{COPD burden}

When queried about their perception of the severity of their COPD, on average a third (29\%, range $14 \%-59 \%)$ of respondents considered their disease mild, a further $48 \%$ stated their disease was moderate (range $40 \%-65 \%$ ), and $23 \%$ reported severe or very severe disease (Figure 4).

A significant COPD burden was demonstrated using validated measures of COPD-specific health status (CAT), dyspnea (mMRC), COPD medication use, and health careresource use (Table 3 and Figure 5). Mean CAT scores ranged from 16.0 in Japan to 24.8 in Brazil, with half of the countries having a mean greater than 20 , indicating high or very high impact on patients' daily lives. Frequency of moderate-tosevere dyspnea ranged from $27 \%$ in Japan to $62 \%$ in the UK. South Koreans reported the lowest use of day and nighttime rescue medication (every day or most days), whereas patients in the UK reported the highest use. Exacerbations (defined as worsening breathing problems in the past 12 months) that resulted in an emergency room visit were reported by $8 \%-61 \%$, and $5 \%-25 \%$ of patients reported at least one hospital admission for an exacerbation (Figure 5).

\section{Discussion}

The Continuing to Confront COPD International Survey sought to estimate the prevalence and burden of COPD in a representative sample of COPD patients, using a range of culturally relevant sampling techniques and a structured survey that incorporated validated PRO instruments. Estimates of COPD prevalence ranged from $7 \%$ to $9 \%$, with the exception of Brazil, which was $12 \%$. In countries that were surveyed in both the current study and the original Confronting COPD International Survey, the estimate of COPD prevalence (smokers and nonsmokers combined) showed an approximate absolute increase of 1\% (Italy, USA, Spain, Germany), 2\% (UK, France), and 4\% (Japan), despite the more restrictive case definition in the current study (requirement of regular medication use or chronic symptoms). ${ }^{16,30}$ Among countries that did not participate in the original Confronting COPD International Survey (Mexico, Russia, South Korea, Brazil), there have been few studies with comparable methodologies and COPD case definitions. A population-based survey using a symptom-based definition of chronic bronchitis (cough and sputum production during the majority of days for at least 3 consecutive months in the previous 2 or more successive years) in Brazil reported a similarly high prevalence (13\%) as observed in the current study (12\%). ${ }^{31}$ Population surveys conducted in Mexico and South Korea using spirometricbased COPD definitions report higher COPD prevalence than the current survey ( $18 \%$ in adults $\geq 40$ years in South Korea, ${ }^{32}$ and $12 \%$ in adults $\geq 40$ years in Mexico ${ }^{15}$ ), which is consistent with findings that COPD prevalence is often higher when based on spirometric criteria compared with patientreported and physician-diagnosed COPD. ${ }^{13,14,33-35}$ 


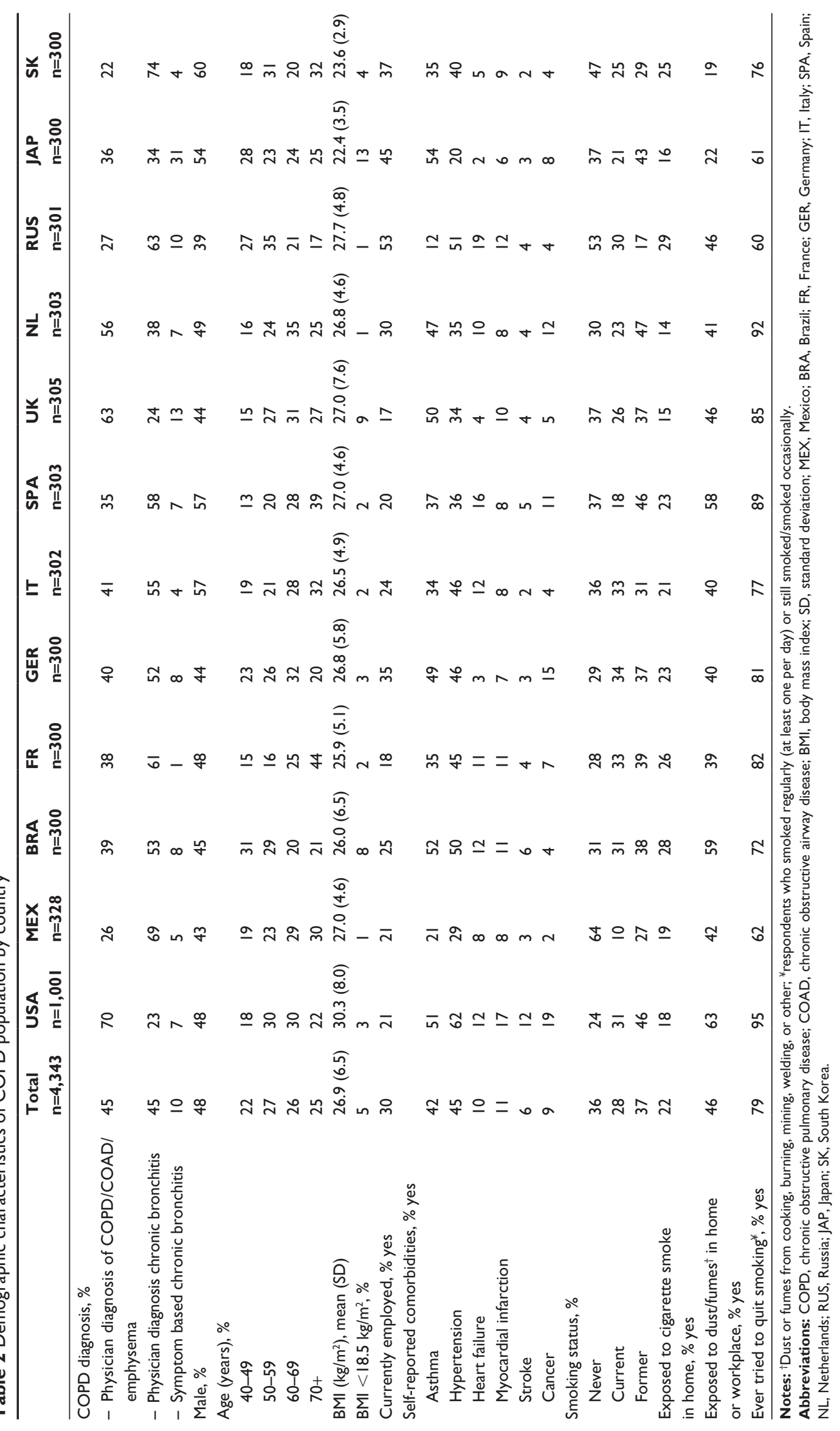




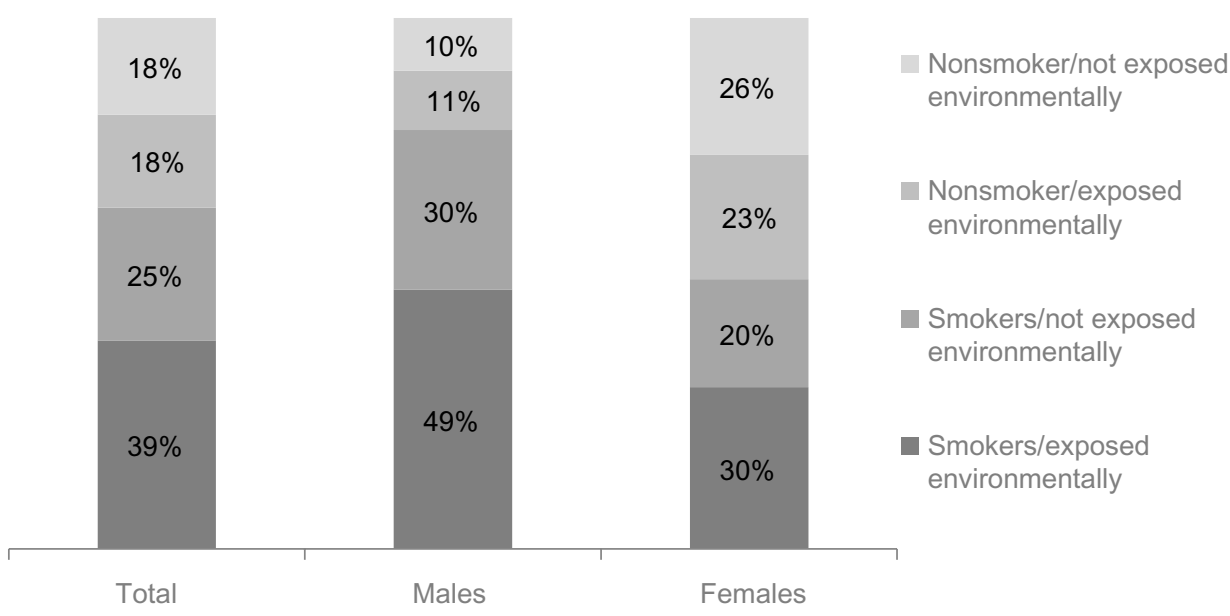

Figure 3 Self-reported tobacco and environmental exposure by sex.

Notes: Smokers included current smokers (smoking cigarettes/cigars/pipe at least once a day) and former smokers (not currently smoking, but had smoked at least 100 cigarettes in their lifetime and at some point smoked on a daily basis). Nonsmokers included those who had smoked fewer than 100 cigarettes in their lifetime or never smoked at all. Exposed environmentally included those reporting secondhand tobacco exposure in their home or that they had lived or worked in a location for more than a year where they were exposed to dust/fumes from cooking, burning, mining, welding, or something else.

As reported in other studies, the estimated COPD prevalence in most countries was higher in men compared with women, and showed a steady increase with age. ${ }^{13-15,34}$ The sex differences were consistent with a higher prevalence of current smokers reported among males. While a majority of our sample were former or current smokers, over a third of the current population (36\%) reported that they had never smoked (range 24\%-64\%). This percentage of never-smokers is higher than reported in the Hidden Depths of COPD survey $(12 \%),{ }^{20}$ but relatively comparable to the US National Health and Nutrition Examination Surveys (32\% for patients with spirometry results suggestive of airway obstruction $)^{34}$ and other studies from high-income countries (20\%-30\% never-smokers). ${ }^{36,37}$ Half of the neversmokers in the current survey reported environmental exposure, such as dust or fumes in the home or workplace, which
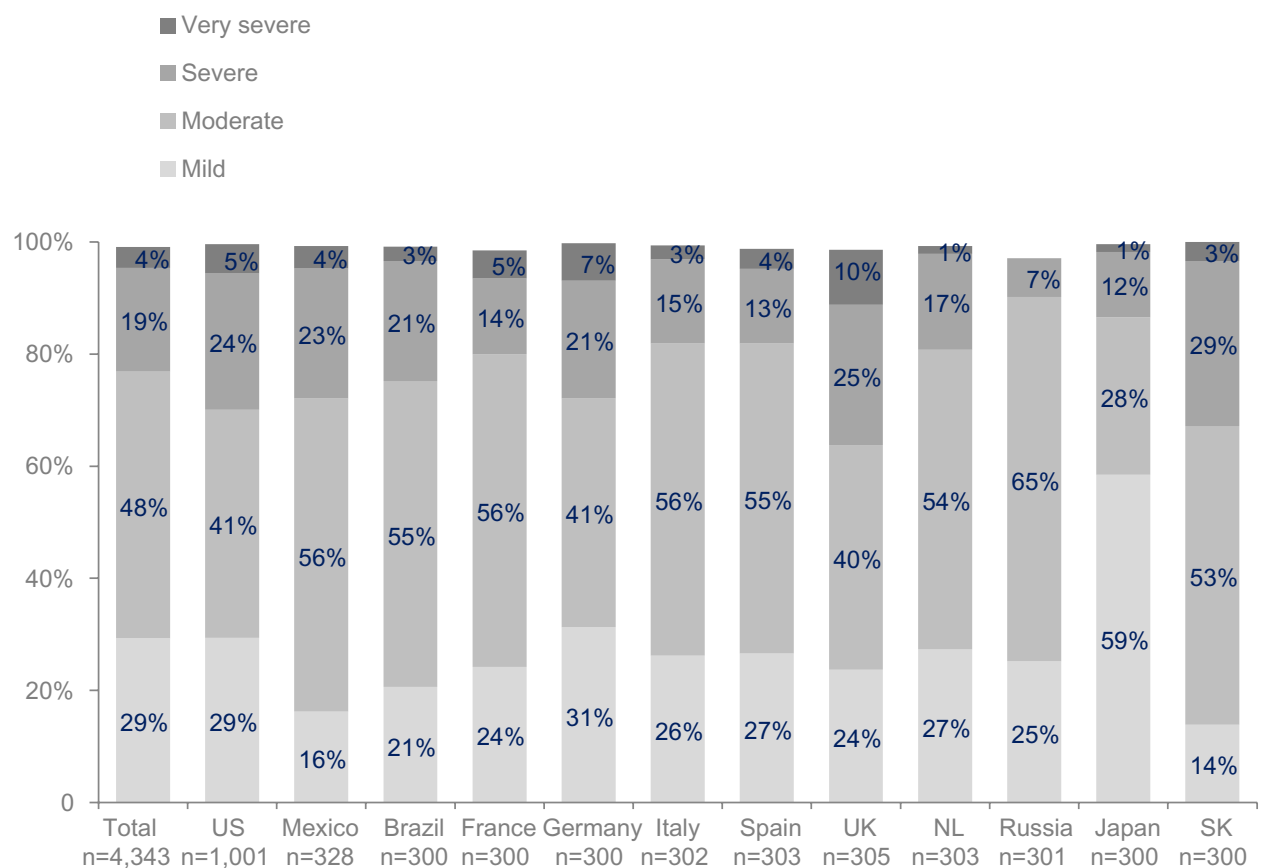

Figure 4 Patient-reported chronic obstructive pulmonary disease severity.

Note: Calculated from response to the question, "Overall, how would you rate your COPD now? Is it very severe, severe, moderate, or mild?" Abbreviations: COPD, chronic obstructive pulmonary disease; NL, Netherlands; SK, South Korea. 


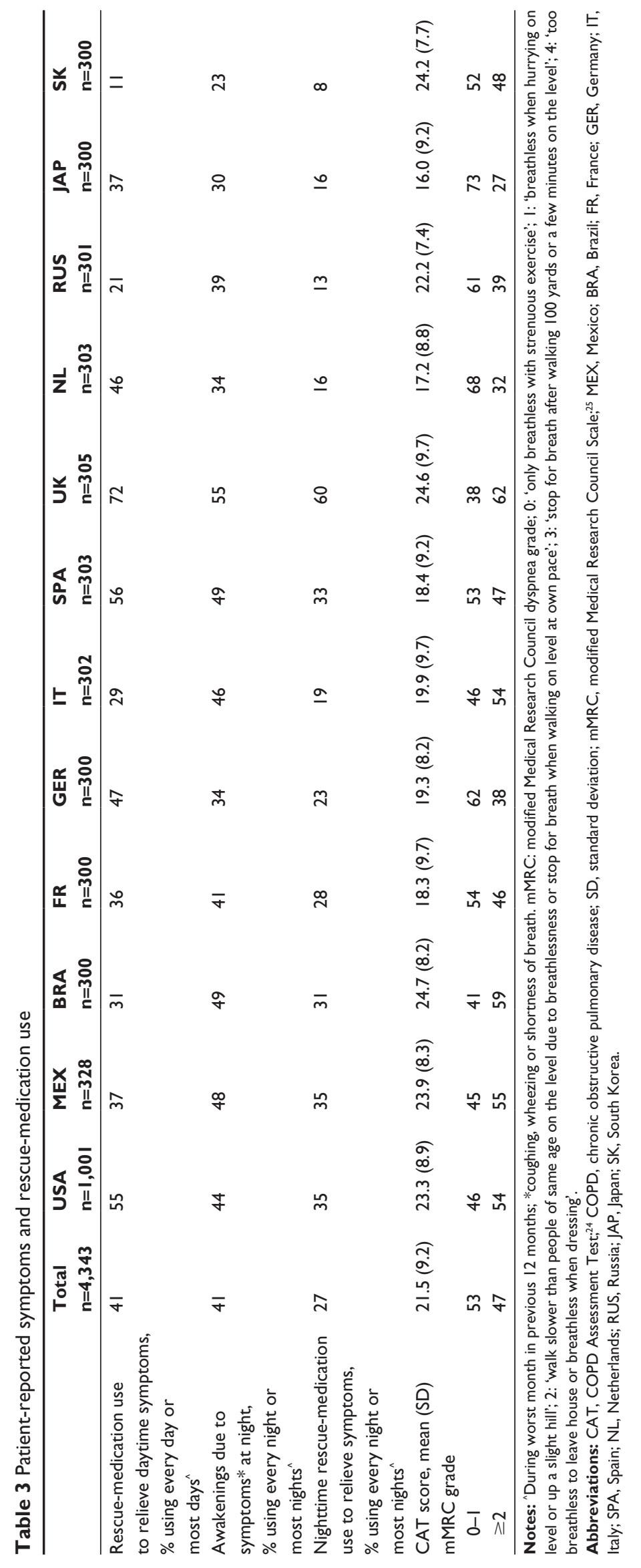




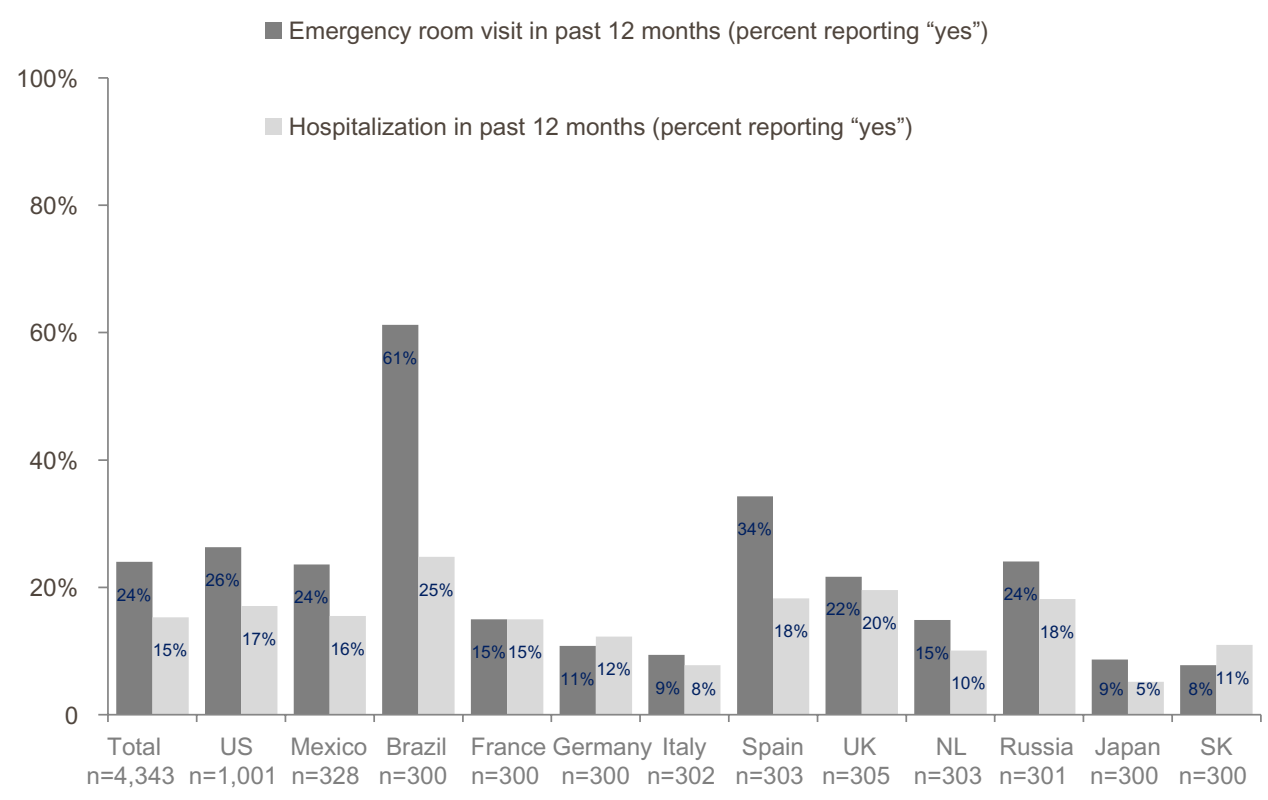

Figure 5 Emergency room visits and hospitalizations due to chronic obstructive pulmonary disease exacerbations in past 12 months.

Notes: Calculated from response to the questions, "In the past 12 months, did any of these episodes (worsening of your breathing problems) require an emergency room visit?" and "In the past 12 months, did any of these episodes (worsening of your breathing problems) require hospitalization?"

Abbreviations: NL, Netherlands; SK, South Korea.

is in line with data from low-income country settings, where up to $60 \%$ of COPD cases may be attributed to causes other than cigarette smoking. ${ }^{38}$ It may be possible that the high rate of COPD observed in the nonsmoking population is attributable to asthma comorbidity; however, we did not see a substantial difference in the presence of asthma self-reported diagnosis over the four smoking/environmental exposure subcategories. Additional risk factors for the development of lung obstruction, such as early respiratory infections or tuberculosis, may have also played a role, but this was not measured in our survey. ${ }^{39}$

Patient-reported COPD burden, including validated measures of symptoms and health status, showed heterogeneity in responses, but indicated a significant impact of the disease on daily activities. Forty-seven percent of patients had moderate-to-severe exercise-related dyspnea (mMRC grade $\geq 2$ ) (range $27 \%-61 \%$ across countries), similar to that reported in the Confronting COPD International Survey ( $43 \%$ for total population) $)^{16}$ and the Hidden Depths of COPD survey (range $25 \%-58 \%$ ). ${ }^{20}$ Six of the 12 countries reported a mean CAT $>20$, indicating severe and very severe burden. ${ }^{28}$ CAT was not measured in the original Confronting COPD International Survey, but the mean CAT scores reported in this study (range 16.0-24.8) were similar to a spirometryclassified COPD population in Europe and the US (range 17.8-21.5). ${ }^{24}$ Approximately $15 \%$ of patients reported a hospitalization due to COPD in the previous 12 months, simi- lar to that reported in the Confronting COPD International Survey (13\%); the proportion reporting an emergency room visit was higher in our survey than that reported previously (24\% versus $14 \%$, respectively). ${ }^{16}$ Brazilian patients reported the highest attendance at an emergency room for an exacerbation $(61 \%)$, which may reflect the urban sampling used for this country. ${ }^{40}$ These results suggest that while COPD appears to have a high or very high impact on patients' daily lives, many patients perceive that their COPD severity is mild or moderate. This discordance was also demonstrated in the original Confronting COPD International Survey, where more than a third of patients who scored the most severe mMRC grade ("Too breathless to leave house") assessed their disease as mild or moderate. ${ }^{16}$ Other studies have shown that patients find it difficult to assess the severity of their disease and symptoms, pointing to the importance of using validated instruments to assess disease and severity and its impact. ${ }^{41}$ The exception in our survey was observed in Japan, where patients were most likely to report their disease as mild (59\%), concordant with this country having the lowest (least severe) mean scores for CAT and mMRC scale. This is also consistent with a high proportion of undiagnosed COPD, as reported in other surveys in Japan..$^{30,33}$

A strength of this survey is that it represents a diverse global population of patients from disparate health care systems with varying COPD-diagnosis practices. Due to the range of settings, intercountry COPD-prevalence 
heterogeneity must be interpreted in the context of the COPD case definition and sampling methodology used. Our case definition included a variety of conditions consistent with how COPD may be diagnosed in different countries, including both physician-diagnosed disease and chronic bronchitis symptomatology without an official diagnosis. The decision to include patients with symptoms only addresses the issue of COPD underdiagnosis and physicians' use of alternative diagnosis terms when speaking to their patients. ${ }^{42,43}$ While only $10 \%$ of the final sample comprised patients who had symptoms only, it is possible that some patients with lung diseases other than COPD may have been included under this definition. For example, a differential diagnosis between asthma and COPD can be challenging, especially when spirometric confirmation is not possible. ${ }^{44,45}$

We did observe variability between counties in the qualifying case definition, with Japan having the highest percentage of patients with the symptom-based criterion (31\%, other countries range $1 \%-13 \%$ ), possibly reflecting a cultural reluctance to diagnosis COPD. Indeed, a high proportion of undiagnosed COPD was seen in Japan in the original Confronting COPD International Survey, ${ }^{30}$ and in another epidemiological survey, which showed only $9.4 \%$ of participants with airflow limitation had a previous diagnosis of COPD. ${ }^{33}$ Another consideration when interpreting prevalence data between countries is differences in sampling techniques. For example, the online health panel used in Japan resulted in a younger sample population, and the largely urban sampling used in Russia and Brazil may have resulted in a population with greater environmental exposure.

Data on COPD burden in terms of symptoms and health care-resource use should also be interpreted within the limitations of self-reported survey techniques. While it was not possible to validate patient-reported exacerbation frequency or medication use with clinical records, we did augment patient-perceived symptom burden and severity of disease with validated PRO instruments. The use of rescue medication to relieve symptoms likely represents not only differences in symptom burden across countries but also cultural variation in access to medication.

In summary, this global survey of patients who met our case definition of COPD (physician-diagnosed COPD or emphysema, or physician-diagnosed or symptom-based chronic bronchitis) reported a prevalence of $7 \%-12 \%$ in a 40 -year or older population, which is greater than reported a decade ago in the Confronting COPD International Survey. Similar to the Confronting COPD International Survey, this updated survey confirms findings that COPD causes a high societal and personal burden, as demonstrated by high levels of symptoms, poor health status, and high frequency of severe exacerbations of COPD. This substantial patient burden is discordant with patients' perceptions of disease severity, emphasizing the importance of utilizing validated patientreported outcomes as part of COPD disease management to improve patient care.

\section{Acknowledgments}

The survey was conducted by Abt SRBI, a global survey research firm that specializes in health surveys. The authors would like to acknowledge editorial support in the form of draft manuscript development, assembling tables and figures, collating author comments, and copyediting, which was provided by Kate Hollingworth of Continuous Improvement Ltd. This support was funded by GlaxoSmithKline (GSK).

\section{Disclosure}

This study was funded by GSK. All authors meet the International Committee for Medical Journal Editors criteria for authorship. SHL, KJD, and HM are employees of GSK and hold GSK shares. DMM, MKH, TvdM, AM, YMO, ZA and MI served on the Scientific Advisory Board for the Continuing to Confront COPD Survey and were paid for advisory services. Scientific Advisory Board members were not paid for authorship services.

\section{References}

1. Global initiative for chronic Obstructive Lung disease. Global Strategy for Diagnosis, Management, and Prevention of COPD. Bethesda (MD): GOLD; 2013. Available from: http://www.goldcopd. org/uploads/users/files/GOLD_Report_2013_Feb20.pdf. Accessed October 30, 2013.

2. Mathers CD, Loncar D. Projections of global mortality and burden of disease from 2002 to 2030. PLoS Med. 2006;3:e442.

3. Lopez AD, Shibuya K, Rao C, et al. Chronic obstructive pulmonary disease: current burden and future projections. Eur Respir J. 2006;27: 397-412.

4. Cully JA, Graham DP, Stanley MA, et al. Quality of life in patients with chronic obstructive pulmonary disease and comorbid anxiety or depression. Psychosomatics. 2006;47:312-319.

5. Carrasco Garrido P, Díez J, Gutiérrez J, et al. Negative impact of chronic obstructive pulmonary disease on the health-related quality of life of patients: results of the EPIDEPOC study. Health Qual Life Outcomes. 2006;4:31.

6. Vermeire P. The burden of chronic obstructive pulmonary disease. Respir Med. 2002;96 Suppl C:S3-S10.

7. Miravitlles M, Ferrer M, Pont À, et al. Effect of exacerbations on quality of life in patients with chronic obstructive pulmonary disease: a 2 year follow up study. Thorax. 2004;59:387-395.

8. Donaldson GC, Wilkinson TM, Hurst JR, Perera WR, Wedzicha JA. Exacerbations and time spent outdoors in chronic obstructive pulmonary disease. Am J Respir Crit Care Med. 2005;171:446-452.

9. Garcia-Aymerich J, Farrero E, Félez MA, Izquierdo J, Marrades RM, Antó JM. Risk factors of readmission to hospital for a COPD exacerbation: a prospective study. Thorax. 2003;58:100-105. 
10. Soler-Cataluña JJ, Martinez-García MA, Román Sánchez P, Salcedo E, Navarro M, Ochando R. Severe acute exacerbations and mortality in patients with chronic obstructive pulmonary disease. Thorax. 2005;60:925-931.

11. Suissa S, Dell'Aniello S, Ernst P. Long-term natural history of chronic obstructive pulmonary disease: severe exacerbations and mortality. Thorax. 2012,67:957-963.

12. Wouters EF. Economic analysis of the Confronting COPD survey: an overview of results. Respir Med. 2003;97 Suppl C:S3-S14.

13. Halbert RJ, Natoli JL, Gano A, Badamgarav E, Buist AS, Mannino DM. Global burden of COPD: systematic review and meta-analysis. Eur Respir J. 2006;28:523-532.

14. Buist AS, McBurnie MA, Vollmer WM, et al. International variation in the prevalence of COPD (the BOLD study): a population-based prevalence study. Lancet. 2007;370:741-750.

15. Menezes AM, Perez-Padilla R, Jardim JR, et al. Chronic obstructive pulmonary disease in five Latin American cities (the PLATINO study): a prevalence study. Lancet. 2005;366:1875-1881.

16. Rennard S, Decramer M, Calverley PMA, et al. Impact of COPD in North America and Europe in 2000: subjects' perspective of Confronting COPD International Survey. Eur Respir J. 2002;20:799-805.

17. Uzaslan E, Mahboub B, Beji M, et al. The burden of chronic obstructive pulmonary disease in the Middle East and North Africa: results of the BREATHE study. Respir Med. 2012;106 Suppl 2:S45-S59.

18. Polatli M, Kheder AB, Wali S, et al. Chronic obstructive pulmonary disease and associated healthcare resource consumption in the Middle East and North Africa: the BREATHE study. Respir Med. 2012; 106 Suppl 22:S75-S85.

19. Fletcher MJ, Upton J, Taylor-Fishwick J, et al. COPD uncovered: an international survey on the impact of chronic obstructive pulmonary disease [COPD] on a working age population. BMC Public Health. 2011;11:612.

20. Barnes N, Calverley PM, Kaplan A, Rabe KF. Chronic obstructive pulmonary disease and exacerbations: patient insights from the global Hidden Depths of COPD survey. BMC Pulm Med. 2013;13:54.

21. CIBA Guest Symposium. Terminology, definitions, and classification of chronic pulmonary emphysema and related conditions. Thorax. 1959;14:286-299.

22. American Thoracic Society Committee on Diagnostic Standards Definitions and classification of chronic bronchitis, asthma, and pulmonary emphysema. Am Rev Respir Dis. 1962;85:762-769.

23. Reilly MC, Zbrozek AS, Dukes EM. The validity and reproducibility of a work productivity and activity impairment instrument PharmacoEconomics. 1993;4:353-365.

24. Jones PW, Harding G, Berry P, Wiklund I, Chen WH, Kline Leidy N Development and first validation of the COPD Assessment Test. Eur Respir J. 2009;34:648-654.

25. Bestall JC, Paul EA, Garrod R, Garnham R, Jones PW, Wedzicha JA. Usefulness of the Medical Research Council (MRC) dyspnoea scale as a measure of disability in patients with chronic obstructive pulmonary disease. Thorax. 1999;54:581-586.

26. Morisky DE, Green LW, Levine DM. Concurrent and predictive validity of a self-reported measure of medication adherence. Med Care. 1986;24:67-74.

27. Hibbard JH, Mahoney ER, Stockard J, Tusler M. Development and testing of a short form of the patient activation measure. Health Serv Research. 2005;40:1918-1930.
28. Jones P, Tabberer M, Chen WH. Creating scenarios of the impact of COPD and their relationship to COPD Assessment Test (CAT $\left.{ }^{\mathrm{TM}}\right)$ scores. BMC Pulm Med. 2011;11:42.

29. [No authors listed]. Obesity: preventing and managing the global epidemic. Report of a WHO Consultation. World Health Organ Tech Rep Ser. 2000;894:i-xii, 1-253.

30. Ichinose M, Hisamichi A, Ishizaka A, et al. [Chronic obstructive pulmonary disease (COPD) burden in Japan - confronting COPD Japan survey]. Nihon Kokyuki Gakkai Zasshi. 2007;45:927-935. Japanese.

31. Menezes AM, Victora CG, Rigatto M. Prevalence and risk factors for chronic bronchitis in Pelotas, RS, Brazil: a population based study. Thorax. 1994;49:1217-1221.

32. Yoo KH, Kim YS, Sheen SS, et al. Prevalence of chronic obstructive pulmonary disease in Korea: the fourth Korean National Health and Nutrition Examination Survey, 2008. Respirology. 2011;16:659-665.

33. Fukuchi Y, Nishimura M, Ichinose M, et al. COPD in Japan: the Nippon COPD Epidemiology study. Respirology. 2004;9:458-465.

34. Ford ES, Mannino DM, Wheaton AG, Giles WH, Presley-Cantrell L, Croft JB. Trends in the prevalence of obstructive and restrictive lung function among adults in the United States: findings from the National Health and Nutrition Examination surveys from 1988-1994 to 2007-2010. Chest. 2013;143:1395-1406.

35. Atsou K, Chouaid C, Hejblum G. Variability of the chronic obstructive pulmonary disease key epidemiological data in Europe: systematic review. BMC Med. 2011;9:7.

36. Hagstad S, Ekerljung L, Lindberg A, Backman H, Rönmark E, Lundbäck B. COPD among non-smokers - report from the obstructive lung disease in Northern Sweden (OLIN) studies. Respir Med. 2012;106: 980-988.

37. Zeng G, Sun B, Zhong N. Non-smoking-related chronic obstructive pulmonary disease: a neglected entity? Respirology. 2012;17:908-012.

38. Lopez A, Mathers CD, Ezzati M, Jamison DT, Murray CJL, editors. Global Burden of Disease and Risk Factors. Washington: World Bank; 2006.

39. Martinez FD. The origins of asthma and chronic obstructive pulmonary disease in early life. Proc Am Thorac Soc. 2009;6:272-277.

40. Arbex MA, de Souza Conceição GM, Cendon SP, et al. Urban air pollution and chronic obstructive pulmonary disease-related emergency department visits. J Epidemiol Community Health. 2009;63: 777-783.

41. Rabe KF, Vermeire PA, Soriano JB, Maier WC. Clinical management of asthma in 1999: the Asthma Insights and Reality in Europe (AIRE) study. Eur Respir J. 2000;16:802-807.

42. Miravitlles M, Soriano JB, Garcia-Rio F, et al. Prevalence of COPD in Spain: impact of undiagnosed COPD on quality of life and daily life activities. Thorax. 2009;64:863-868.

43. Fukuhara S, Nishimura M, Nordyke RJ, Zaher CA, Peabody JW. Patterns of care for COPD by Japanese physicians. Respirology. 2005;10: 341-348.

44. Kim SR, Rhee YK. Overlap between asthma and COPD: where the two diseases converge. Allergy Asthma Immunol Res. 2010;2: 209-214.

45. Melbye H, Drivenes E, Dalbak LG, Leinan T, Høegh-Henrichsen S, Ostrem A. Asthma, chronic obstructive pulmonary disease, or both? Diagnostic labeling and spirometry in primary care patients aged 40 years or more. Int J Chron Obstruct Pulmon Dis. 2011;6:597-603. 


\section{Supplementary materials Materials and methods}

\section{Subject selection}

COPD patients were identified systematically by screening probability samples of households using three sampling approaches.

\section{Random-digit dialing}

In countries with high rates of telephone coverage (France, Germany, Italy, Netherlands, Spain, UK, USA), households were sampled by RDD of a nationally representative sample of landline-telephone households, and respondents were interviewed by CATI. The RDD sampling procedure randomly selects blocks of numbers from all theoretically possible landline telephone numbers based on area codes and exchanges (typically blocks of 100, based on the last two digits). The sampling was stratified by region, and produced a nationally representative sample by region and the urban/ rural population. Households were screened for any persons aged 40 years or older. If more than one person fulfilled the age criterion, the program randomly selected an individual to participate. Respondents were then screened for COPD according to the questionnaire qualifying criteria. Up to five attempts were made to recruit the selected respondent, and callback attempts were conducted at different times of the day and different days of the week to maximize potential contact and cooperation.

\section{Area-probability sampling}

In countries with poor or variable telephone coverage in some regions (Brazil, Mexico, Russia, South Korea), households were sampled by area-probability sampling of urban areas, and respondents were interviewed face to face. Sampling was restricted to urban areas, due to the fieldwork costs of screening a large number of households face to face.

The urban population was sampled by region and roughly proportionate to population size. States/districts and then the smallest administrative units were selected by a random procedure. Primary sampling units were randomly selected and starting points assigned (an address or quadrant/block) within each cluster. Interviewers conducted a random route walk from the starting point, contacting households to conduct the screener interview. A maximum of five interviews per cluster were allowed for the sampling design; the maximum actually attained during the course of fieldwork in all four countries was three interviews per cluster. The households were screened for any persons aged 40 years or older. If more than one person was aged 40 years or older, the Kish ${ }^{1}$ random-selection method was used to select an individual to participate. Respondents were then screened for COPD according to the questionnaire qualifying criteria. After each completed screening (if no qualifying patient was selected) or each completed interview with a COPD patient, three households were skipped. A maximum of two qualified interviews were allowed in multistory buildings, and a floor was skipped after each qualified interview. Up to three attempts were made to recruit the selected respondent, and callback attempts were conducted at different times of the day and different days of the week to maximize potential contact and cooperation.

\section{Online panel of prescreened COPD and chronic bronchitis patients}

The survey in Japan was initially designed as a telephone survey, with a sample drawn by RDD. However, after 3 weeks of fieldwork, the survey team determined that Japanese respondents were not comfortable when approached at random to discuss respiratory conditions. The incidence rate of qualified COPD patients was $0.8 \%$.

Consequently, an online health panel that was demographically representative of the Japanese population was used for sampling and screening COPD patients. A sample of patients aged 40 years or older was then invited to be screened for COPD according to the questionnaire qualifying criteria. Respondents who accepted the invitation were then contacted by telephone, screened, and further interviewed if they fulfilled the COPD case criteria. As with the other countries, respondents who met the case definition of COPD were then interviewed by CATI. Up to three attempts were made to recruit the selected respondent, and callback attempts were conducted at different times of the day and different days of the week to maximize potential contact and cooperation.

This survey qualified for institutional review board exemption, as the following criteria were met: involved no medicine administration, medical devices, or biospecimen collection; respondent participation was voluntary; there was no respondent burden other than completion of the survey; the survey population was not a vulnerable population (any elderly respondents could opt out at any time, and interviewers were trained to terminate interviews with any respondents struggling with cognitive or health issues); the survey was not conducted for litigation purposes; the survey did not collect sensitive data; there were no risks of data disclosure; and respondents could not be named or identified directly or indirectly. 
In countries where face-to-face interviews were conducted in the respondents' home, modest incentives may have been offered, the value of which was less than US\$6 (eg, mobile phone top-up card, tea, chocolates). In Japan, the members of the online panel were compensated by the panel provider directly, typically $\$ 11$. No other incentives were provided.

\section{Case definition of COPD}

The case definition for COPD was adults $\geq 40$ years meeting one of the following definitions:

- physician diagnosis of COPD, chronic obstructive airway disease, or emphysema, and either regularly used medication to treat these conditions or had chronic cough with phlegm most days

- physician diagnosis of chronic bronchitis and either regularly used medication to treat this condition or had chronic cough with phlegm most days

- chronic bronchitis defined by symptomatology (cough and sputum production on most days for at least 3 months in the year for at least 2 consecutive years ${ }^{2,3}$ ) and either regularly used medication to treat this condition or had chronic cough with phlegm most days.

Eligibility was determined using a hierarchal approach, such that a respondent who qualified with a physician diagnosis of COPD, chronic obstructive airway disease, or emphysema was not further queried to see if they also qualified based on physician diagnosis of chronic bronchitis. A flowchart of how the sample of 4,343 patients qualified for the survey is shown in Figure S1.

\section{Data collection}

The finalized English-language questionnaire was translated into local languages by an independent translator who was a native of the target country and who had experience in translating health surveys. As part of the translation process, the translation was reviewed by a second independent translator, as well as the in-country survey team, to ensure that the intent of the English-language questionnaire was conveyed correctly and translations were culturally appropriate.

The interviews were conducted using the local language questionnaire and lasted on average 36 minutes (Table S1). Response rates ranged from 26\% in France to $74 \%$ in Brazil (Table S2). Response rates were the highest in the countries surveyed face to face (Mexico 74\%, Brazil 72\%, South Korea $68 \%$, and Russia $63 \%$ ), because this mode is more likely to successfully reach and screen households. Response rates for the countries surveyed by telephone were lower by comparison, given the ease with which respondents can avoid contact and refuse to participate (US $43 \%$, Italy $39 \%$, Netherlands

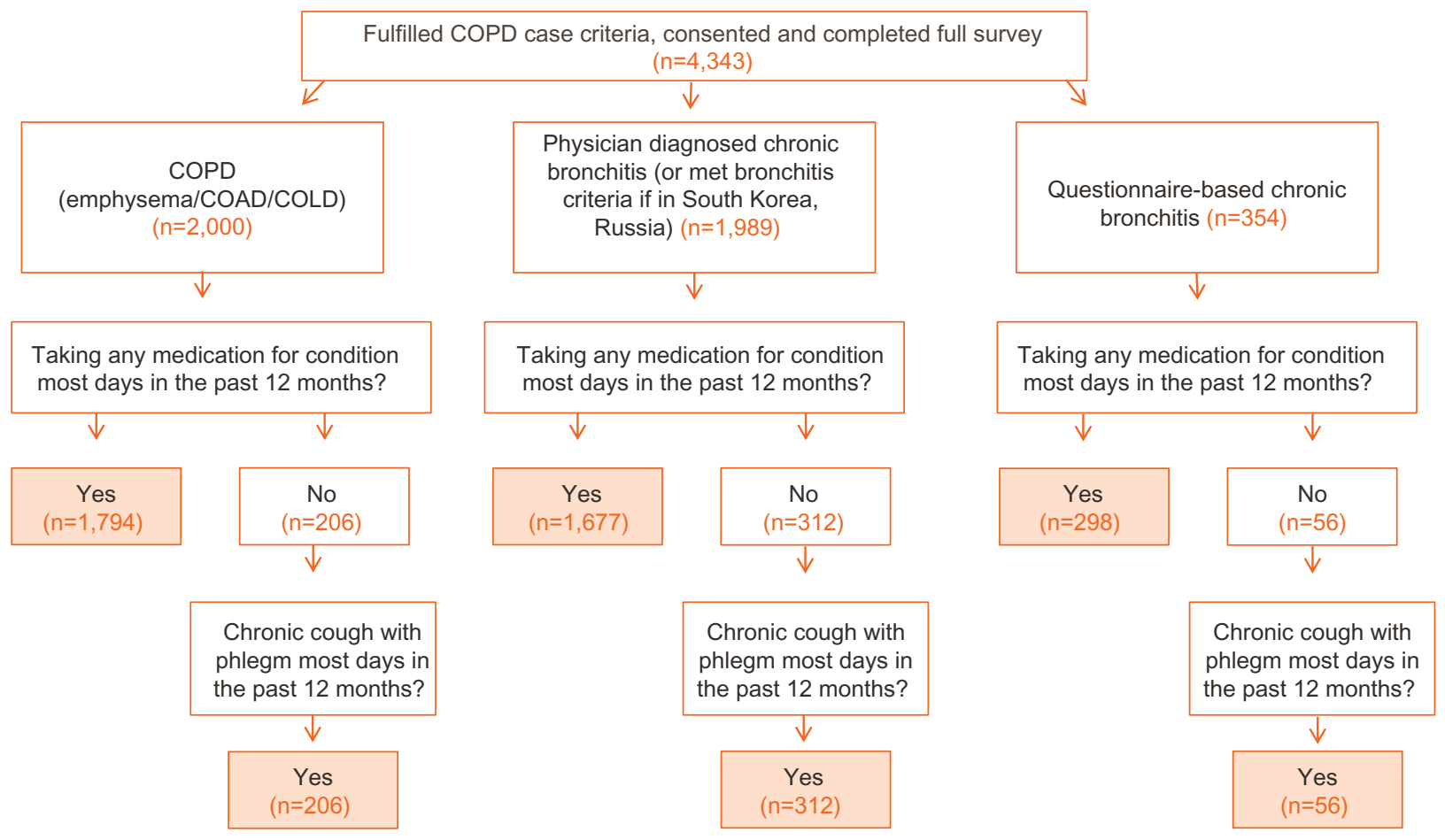

Figure SI Flowchart of COPD definition among patients completing full survey.

Note: NB: n's are unweighted.

Abbreviation: COPD, chronic obstructive pulmonary disease; COAD, chronic obstructive airway disease; COLD, chronic obstructive lung disease. 
Table SI Patient survey mode, language and interview length

\begin{tabular}{llll}
\hline Country & Survey mode & Languages & $\begin{array}{l}\text { Average } \\
\text { interview } \\
\text { length (minutes) }\end{array}$ \\
\hline USA & Telephone & English/Spanish & 32 \\
Mexico & Face to face & Spanish & 49 \\
Brazil & Face to face & Portuguese & 42 \\
France & Telephone & French & 32 \\
Germany & Telephone & German & 37 \\
Italy & Telephone & Italian & 34 \\
Spain & Telephone & Spanish & 33 \\
UK & Telephone & English & 35 \\
Netherlands & Telephone & Dutch & 36 \\
Russia & Face to face & Russian & 44 \\
Japan & Online*/ & Japanese & 36 \\
& Telephone & & \\
South Korea & Face to face & Korean & 37 \\
Total & & & 36 \\
\hline Note: & &
\end{tabular}

Note: *Patients in Japan were recruited from an online health panel. Interviews were administered by telephone.

$33 \%$, Germany $32 \%$, Spain $31 \%$, France $26 \%$, and UK $25 \%$ ). The response rate for Japan (51\%) was somewhere in between, which reflects a high noncontact and refusal rate for the online screening portion but an extremely high cooperation rate for the telephone-interviewing portion.

The following validated PRO instruments were included in the survey using the approved translations.

\section{Modified Medical Research Council Dyspnea Scale}

The mMRC Dyspnea Scale is a measure of five grades of breathlessness due to physical exertion, and is self-rated by the patient to indicate how much their breathlessness affects their mobility. ${ }^{4}$ The five grades are 0 ("I only get breathless with strenuous exercise"), 1 ("I get short of breath when hurrying on the level or up a slight hill"), 2 ("I walk slower than people of the same age on the level because of breathlessness or have to stop for breath when walking at my own pace on

Table S2 Patient survey response rates

\begin{tabular}{ll}
\hline Country & Response rate \\
\hline USA & $43 \%$ \\
Mexico & $72 \%$ \\
Brazil & $74 \%$ \\
France & $26 \%$ \\
Germany & $32 \%$ \\
Italy & $39 \%$ \\
Spain & $31 \%$ \\
UK & $25 \%$ \\
Netherlands & $33 \%$ \\
Russia & $63 \%$ \\
Japan & $51 \%$ \\
South Korea & $68 \%$ \\
\hline
\end{tabular}

the level"), 3 ("I stop for breath after walking 100 yards or after a few minutes on the level"), and 4 ("I am too breathless to leave the house").

\section{COPD Assessment Test}

The CAT is an eight-item, self-administered health-status questionnaire that measures current symptoms and impact of COPD. ${ }^{5}$ The eight questions relate to cough, phlegm, chest tightness, breathlessness going up hills/stairs, activity limitations at home, confidence leaving home, sleep, and energy. CAT scores range from 0 to 40 , representing the patient's best and worst health status, respectively.

\section{Work Productivity and Activity Impairment}

The WPAI questionnaire measures impact due to poor health on work, described as: absenteeism or percentage of time missed from work; presenteeism or percentage of impairment while working; percentage overall work-productivity impairment, which considers both absenteeism and presenteeism; and percentage impairment in daily activities. ${ }^{6}$ Higher percentages indicate greater impairment and less productivity. The recall period of the WPAI is 7 days.

\section{Patient Activation Measure}

The short-form PAM is a 13-item questionnaire that measures a patient's self-confidence in their role in managing their disease and their assertiveness in dealing with the health care system. ${ }^{7}$ This scale includes such measures as responsibility for managing their health condition, taking an active role, confidence in minimizing symptoms, knowing what medications do, knowing when to seek care, ability to tell provider about concerns, ability to follow through with treatments at home, understanding the nature of their health condition, knowing the treatment options available, able to maintain lifestyle changes, knowing how to prevent further problems, confidence in figuring out solutions to new problems, and confidence in maintaining lifestyle changes even during times of stress. Patients were asked to rate each question as 1 (totally disagree), 2 (somewhat disagree), 3 (somewhat agree), or 4 (totally agree). The PAM yields a theoretical score from 0 to 100 , and patients were assigned a PAM level based on this score:

- level 1 (PAM score of 47.0 or lower) - starting to take a role

- level 2 (PAM score of 47.1-55.1) - building knowledge and confidence

- level 3 (PAM score of 55.2-67.0) - taking action

- level 4 (PAM score of 67.1 or above) - maintaining behaviors. 


\section{Morisky Adherence Scale}

The Morisky eight-item Medication Adherence Scale (Morisky-8). Its predictive value has been explored for treatment with antihypertensive agents, ${ }^{8}$ but little is known about its predictive value for other conditions. This scale includes such measures as forgetting to take medicine, missing medicine for other reasons in the past 2 weeks, cutting back or stopping taking medicine, forgetting to take medicine when away from home, sometimes stopping medicine when symptoms are under control, feeling hassled about sticking to treatment plan, and difficulty in remembering to take all of the medicine.

The first seven items are dichotomous, and the last contains a Likert scale. Six of the eight items address general adherence rather than over a specific time scale, and items two and five address adherence over a fortnight and a day, respectively. The Morisky- 8 produces an overall adherence score that ranges from 1 to 8 , a higher score indicating a greater extent of adherence. Respondents can also be classified as low (score 1-5), medium (score 6-7), or high (score 8) adherers according to their overall score.

\section{References}

1. Kish L. Survey Sampling. New York: John Wiley \& Sons; 1965.

2. CIBA Guest Symposium. Terminology, definitions, and classification of chronic pulmonary emphysema and related conditions. Thorax. 1959;14:286-299.

3. American Thoracic Society Committee on Diagnostic Standards. Definitions and classification of chronic bronchitis, asthma, and pulmonary emphysema. Am Rev Respir Dis. 1962;85:762-769.

4. Bestall JC, Paul EA, Garrod R, Garnham R, Jones PW, Wedzicha JA. Usefulness of the Medical Research Council (MRC) dyspnoea scale as a measure of disability in patients with chronic obstructive pulmonary disease. Thorax. 1999;54:581-586.

5. Jones PW, Harding G, Berry P, Wiklund I, Chen WH, Kline Leidy N. Development and first validation of the COPD Assessment Test. Eur Respir J. 2009;34:648-654.

6. Reilly MC, Zbrozek AS, Dukes EM. The validity and reproducibility of a work productivity and activity impairment instrument Pharmacoeconomics. 1993;4:353-365.

7. Hibbard JH, Mahoney ER, Stockard J, Tusler M. Development and testing of a short form of the Patient Activation Measure. Health Serv Res. 2005;40:6.

8. Morisky DE, Ang A, Krousel-Wood M, Ward HJ. Predictive validity of a medication adherence measure in an outpatient setting. JClin Hypertens (Greenwich). 2008;10:348-354.

\section{Publish your work in this journal}

The International Journal of COPD is an international, peer-reviewed journal of therapeutics and pharmacology focusing on concise rapid reporting of clinical studies and reviews in COPD. Special focus is given to the pathophysiological processes underlying the disease, intervention programs, patient focused education, and self management protocols.

\section{Dovepress}

This journal is indexed on PubMed Central, MedLine and CAS. The manuscript management system is completely online and includes a very quick and fair peer-review system, which is all easy to use. Visit http://www.dovepress.com/testimonials.php to read real quotes from published authors. 